\title{
Papers
}

\section{Effect of zinc supplementation started during diarrhoea on morbidity and mortality in Bangladeshi children: community randomised trial}

Abdullah H Baqui, Robert E Black, Shams El Arifeen, Mohammad Yunus, Joysnamoy Chakraborty, Saifuddin Ahmed, J Patrick Vaughan

\begin{abstract}
Objective To evaluate the effect on morbidity and mortality of providing daily zinc for 14 days to children with diarrhoea.

Design Cluster randomised comparison.

Setting Matlab field site of International Center for Diarrhoeal Disease Research, Bangladesh.

Participants 8070 children aged 3-59 months contributed 11881 child years of observation during a two year period.

Intervention Children with diarrhoea in the intervention clusters were treated with zinc (20 mg per day for 14 days); all children with diarrhoea were treated with oral rehydration therapy.

Main outcome measures Duration of episode of diarrhoea, incidence of diarrhoea and acute lower respiratory infections, admission to hospital for diarrhoea or acute lower respiratory infections, and child mortality.

Results About 40\% (399/1007) of diarrhoeal episodes were treated with zinc in the first four months of the trial; the rate rose to $67 \%(350 / 526)$ in month 5 and to $>80 \%(364 / 434)$ in month 7 and was sustained at that level. Children from the intervention cluster received zinc for about seven days on average during each episode of diarrhoea. They had a shorter duration (hazard ratio $0.76,95 \%$ confidence interval 0.65 to 0.90 ) and lower incidence of diarrhoea (rate ratio $0.85,0.76$ to 0.96 ) than children in the comparison group. Incidence of acute lower respiratory infection was reduced in the intervention group but not in the comparison group. Admission to hospital of children with diarrhoea was lower in the intervention group than in the comparison group $(0.76,0.59$ to 0.98$)$. Admission for acute lower respiratory infection was lower in the intervention group, but this was not statistically significant $(0.81$, 0.53 to 1.23). The rate of non-injury deaths in the intervention clusters was considerably lower $(0.49$, 0.25 to 0.94 ).
\end{abstract}

Conclusions The lower rates of child morbidity and mortality with zinc treatment represent substantial benefits from a simple and inexpensive intervention that can be incorporated in existing efforts to control diarrhoeal disease.

\section{Introduction}

Zinc deficiency is highly prevalent in children in developing countries. ${ }^{1}$ Inadequacy of dietary zinc intake is exacerbated by the net loss of zinc during diarrhoea. ${ }^{2}$ Zinc supplements given during diarrhoea reduce the duration and severity of treated episodes ${ }^{3}$ and, if given for 14 days during and after diarrhoea, can reduce the incidence of diarrhoea and acute lower respiratory infection in the subsequent two to three months. ${ }^{4}$ Provision of zinc during diarrhoea may thus be a feasible strategy for both treatment of diarrhoea and prevention of subsequent morbidity and mortality. The therapeutic trials of zinc supplementation conducted to date have been small and conducted in clinical settings. We aimed to evaluate the impact on morbidity and mortality of zinc treatment during diarrhoea in a realistic large scale public health programme.

The study was based on the premises that the dietary intake of zinc of most Bangladeshi children is marginal, that many children become deficient during episodes of diarrhoea, and that treatment of diarrhoea with zinc will help to maintain an adequate zinc balance and tissue function. We hypothesised that zinc supplements given as treatment for two weeks in addition to oral rehydration treatment for all episodes of diarrhoea in preschool children in Bangladesh would reduce the duration of the treated episodes, the incidence of diarrhoea and acute lower respiratory infection, the number of admissions to hospital related to diarrhoea or acute lower respiratory infections, and mortality.

\section{Methods}

Study design and population

We conducted this community based, prospective, randomised controlled trial in the Matlab field area of the International Center for Diarrhoeal Disease Research, Bangladesh (ICDDR,B): Centre for Health and Population Research in Bangladesh. Matlab is a rural subdistrict of Bangladesh where diarrhoea related research has been conducted since 1963. A health and

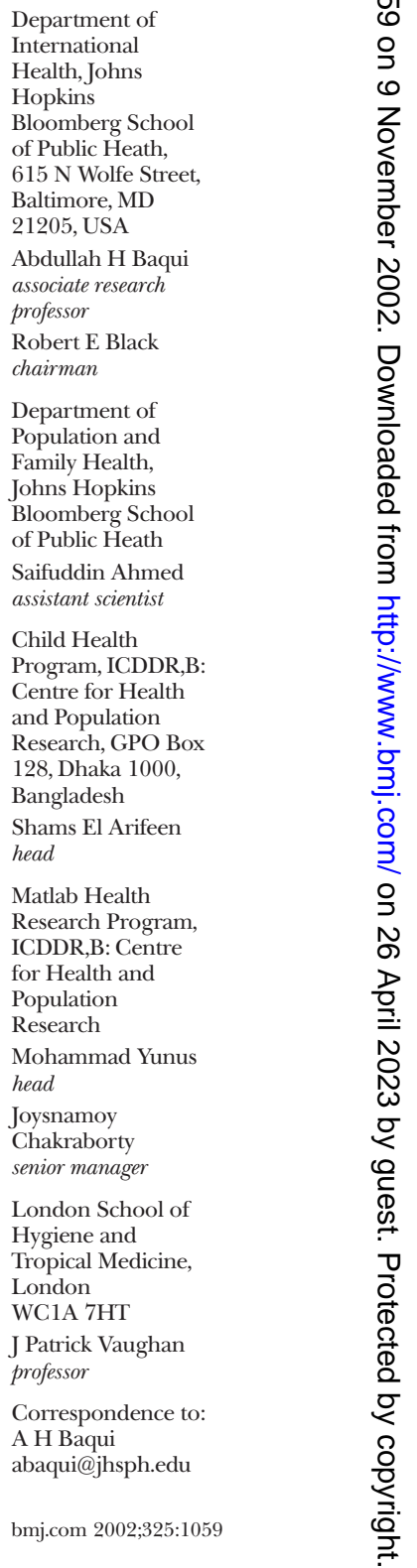


demographic surveillance system established in 1966 now operates in 144 villages with 210000 people. This surveillance system gathers vital event information on births, deaths, and migrations on a regular basis through home visits. In 1998 infant mortality in the Matlab area was 60.6 per 1000 live births, and mortality in children aged 1-4 years was 5.2 per 1000 children. Diarrhoea accounted for about $12 \%$ of infant deaths and about a third of all deaths in children aged 1-4 years. ${ }^{5}$

Since the inception of research in the Matlab area patients with severe diarrhoea have been cared for in a treatment centre at Matlab township, and patients with severe acute lower respiratory infection have also been treated there since 1980. Oral rehydration treatment and referral for patients with diarrhoea are provided in the villages by community health workers and by Bari mothers-community volunteers who distribute oral rehydration solution packets and provide advice to patients with diarrhoea. The community health workers also provide treatment and referral services for acute lower respiratory infection. On average, there is one community health worker for every 2000 people and one Bari mother for every 50 people.

We selected for the study 30 service areas (clusters) of community health workers around Matlab treatment centre, each with about 200 children aged 3-47 months. We calculated sample size on the basis of a method by Donner et al, ${ }^{6}$ with $80 \%$ power, $95 \%$ confidence level, and a design effect of 3 to detect assumed differences between the intervention and comparison groups for the five primary outcomes-duration of diarrhoea, incidence of diarrhoea and acute lower respiratory infection, and admission to hospital for diarrhoea or acute lower respiratory infection. Our final sample size, 11772 child years of observation, was the highest sample size needed to detect a 33\% reduction in annual hospital admissions for acute lower respiratory infection from a baseline rate of 6 per 100 child years. We expected two years' follow up of children aged 3-59 months in the areas of 30 community health workers to provide the required number of child years of observation. Accordingly, we selected 30 community health worker service areas. Because data for the entire two year period was not necessary for assessment of the effects on duration of diarrhoeal episodes and on incidence of diarrhoea and acute lower respiratory infection, we collected data for these outcomes from samples of episodes and samples of time periods.

We observed considerable variation in baseline rates of admission to hospital for diarrhoea between clusters. To minimise baseline differences in rates of admission for diarrhoea between intervention and comparison groups, we calculated the baseline rates by study cluster for 1996-7. We assigned clusters to three strata defined by baseline admission rates and randomly selected clusters within each stratum for intervention or comparison.

We initially enrolled children aged 3-47 months who were permanent residents of the study cluster areas. We also included all babies as they became 3 months old and all babies in the age range of 3-59 months moving into the area during the period of the study, November 1998 to October 2000. Children with a mid-upper arm circumference of $<110 \mathrm{~mm}$ were excluded and referred to the Matlab treatment centre for care. When study children became 60 months old they were excluded.

The ethical review committees of ICDDR,B and the Johns Hopkins School of Public Health approved the study procedures. Because this was a community based treatment trial, we obtained consent from the villages through meetings that explained the purpose of the study and potential risks and benefits of the new treatment. We obtained verbal informed consent for data collection from parents of intervention and comparison group children.

\section{Intervention}

The community health workers and Bari mothers in the intervention clusters taught the mothers how to use the zinc syrup. As soon as diarrhoea was reported, study children in the intervention villages were to receive $20 \mathrm{mg}$ of elemental zinc as acetate each day for 14 days, regardless of the duration of the episode, in a once daily dose of $5 \mathrm{ml}$. ACME Laboratories (Dhaka, Bangladesh) prepared the syrup, and the biochemistry laboratory of ICDDR,B independently confirmed its zinc content. The children in the intervention and comparison clusters received oral rehydration solution, and their mothers received advice on feeding during diarrhoea and on referral to the Matlab treatment centre, if needed.

\section{Outcome definitions and follow up}

Data collectors $(n=12)$ who were not involved in the implementation of the intervention made bi-monthly home visits (six monthly in the second year of the study) to collect data on morbidity from diarrhoea and acute lower respiratory infection and adherence to zinc treatment. The recall period was one week for diarrhoea and two weeks for acute lower respiratory infection. Diarrhoea was defined as three or more loose, liquid, or watery stools or at least one loose stool containing blood in a 24 hour period. If the stool contained blood, the episode was classified as dysentery. Acute lower respiratory infection was diagnosed if the child had reported symptoms of cough, difficult breathing and rapid breathing, or chest in-drawing. To determine the duration of diarrhoeal episodes, each data collector selected the first two active diarrhoeal episodes (episodes that started within 48 hours of the visit by the data collector and were continuing during the visit) each week and followed them every third day until they were resolved. Data on hospital admissions related to diarrhoea or acute lower respiratory infection (diagnosis made by physician) were collected by surveillance in the Matlab treatment centre. Data on deaths in study children were collected by the health and demographic surveillance system of ICDDR,B, which is independent of the study. Verbal autopsy was conducted with the parents for all reported deaths by using a standardised structured questionnaire to determine the causes of death, which were assigned with a computer algorithm. ${ }^{7}$ To ensure data quality, the study supervisors and investigators made spot checks, and a $5 \%$ sample of study children's parents were re-interviewed within two days of the original visit. Data were entered using online programs with checks of range and consistency.

We used data on follow up of selected diarrhoeal episodes to determine the duration of episodes. We 


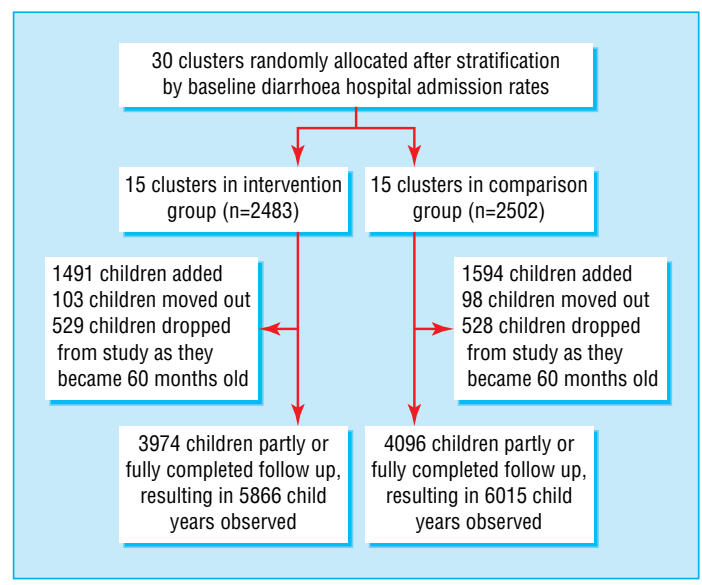

Fig 1 Trial profile

used recall periods for diarrhoea and acute lower respiratory infection for which data were available as denominators for calculating the incidence of diarrhoea and acute lower respiratory infection. We used child years of passive surveillance calculated by subtracting the entry date of the child in the study from his or her exit date as the denominator to calculate hospital admission and death rates.

We controlled for any significant baseline differences during data analysis. We used a Cox's hazards regression to assess the therapeutic effect of zinc on the duration of diarrhoeal episodes, ${ }^{8}$ and we estimated the effects of zinc treatment on other outcomes in two ways. Firstly, using children as the unit of analysis, we calculated rates, rate ratios, and $95 \%$ confidence intervals, adjusting for covariates with random effect Poisson regression. ${ }^{9}$ The model took into account the duration of exposure for each child and the effect of intracluster correlation. Secondly, we conducted a cluster level analysis in which we used Student's $t$ test to compare the mean rates in the intervention and comparison clusters adjusted for the distribution of selected characteristics of children. ${ }^{6}{ }^{10}$ The cluster level $t$ test provides $t$ and $\mathrm{P}$ values and also provides differences in mean rates and 95\% confidence intervals. (Because the confidence interval is around the differences of mean rates, if it does not include zero the groups are significantly different). We used Stata software, version 7 , to analyse the data.

\section{Results}

At the beginning of the study, the 15 intervention clusters contained 2483 children aged 3-47 months and the 15 comparison clusters contained 2502 children. The trial profile (fig 1) shows the numbers of new children added and children who moved out or who were dropped from the study at 60 months of age. A total of 8070 children contributed 11881 child years of observation. The age distribution of children in the intervention cluster was similar to that in the comparison cluster (table 1). Significantly more boys were in the intervention clusters than the comparison clusters. The distribution of children's age and birth order, mothers' education, homestead land size, and baseline diarrhoea hospital admission rates were similar in the intervention and comparison clusters (table 2).
About 40\% (399/1007) of episodes were treated with zinc in the first four months of the trial. Use of zinc increased to about $67 \%(350 / 526)$ of episodes by month 5 of the trial and to more than $80 \%(364 / 434)$ by month 7 , and was sustained at that level. On average, intervention children received zinc for about seven days during each episode of diarrhoea.

We followed 620 diarrhoeal episodes in the intervention clusters and 632 episodes in the comparison clusters. The duration of diarrhoea in children from the intervention clusters was $24 \%$ shorter than that in the comparison group; the duration was significantly shorter for both non-dysenteric diarrhoea and dysentery (table 3).

Many children were part of the study for less than two years. If the study children had contributed data for all periods while they were in the study, data from 46880 recall periods would have been generated. Data were available for $41788(89 \%)$ periods. The incidence of diarrhoea was $15 \%$ lower in the intervention clusters than in the comparison clusters (table 4). The cluster level analysis confirmed this finding $(\mathrm{P}<0.01)$. A slightly lower incidence of acute lower respiratory infection in the intervention clusters was evident by the end of the study, but the difference in rates between the intervention and comparison groups over the full study period was not significant. The intervention clusters had a much higher incidence of acute lower respiratory infection than the comparison clusters at the start, and this incidence declined significantly over the study period. No such trend was observed in the comparison clusters (fig 2). The trends in incidence of acute lower respiratory infection in the intervention and comparison clusters were significantly different when tested using variance weighted least squares regression $(\mathrm{P}<0.001)$.

Children in the intervention clusters had a $24 \%$ lower diarrhoea related admission rate than children in the comparison clusters, which was a significant difference in the individual level analysis but not in the cluster analysis. The admission rate for acute lower respiratory infection was also lower (by 19\%) in the

Table 1 Distribution of children by age and study group

\begin{tabular}{lccc} 
& \multicolumn{3}{c}{ Child years observed } \\
\cline { 2 - 4 } Age (months) & Intervention & Comparison & Total \\
\hline $3-5$ & 328.5 & 342.3 & 670.8 \\
\hline $6-11$ & 690.6 & 707.9 & 1398.5 \\
\hline $12-23$ & 1383.4 & 1409.3 & 2792.7 \\
\hline $24-35$ & 1322.8 & 1304.6 & 2627.4 \\
\hline $36+$ & 2140.6 & 2250.6 & 4391.2 \\
\hline Total & 5865.9 & 6014.7 & 11880.6 \\
\hline
\end{tabular}

Table 2 Selected characteristics of children at entry to study. Values are means (95\% confidence intervals) unless stated otherwise

\begin{tabular}{lcc} 
Characteristics & Intervention $(\mathbf{n}=\mathbf{1 5})^{*}$ & Comparison $(\mathbf{n}=\mathbf{1 5})$ \\
\hline Age (months) & $18.1(17.6$ to 18.7$)$ & $18.2(17.7$ to 18.7$)$ \\
\hline Sex (\% female) & $47.9(46.8$ to 49.1$)$ & $50.9(49.3$ to 52.4$)$ \\
\hline Birth order & $2.7(2.5$ to 2.8$)$ & $2.6(2.5$ to 2.7$)$ \\
\hline Mother's years of completed schooling & $3.6(3.0$ to 4.2$)$ & $3.8(3.2$ to 4.4$)$ \\
\hline Homestead land in decimal & $10.4(9.0$ to 11.8$)$ & $10.1(8.5$ to 11.7$)$ \\
\hline Baseline rate of admission to hospital for diarrhoeat & $8.1(6.1$ to 10.2$)$ & $8.1(6.1$ to 10.3$)$ \\
\hline
\end{tabular}

${ }^{*}$ Confidence intervals based on cluster level standard error.

†Per 100 child years observed. 
Table 3 Effect of zinc on duration of diarrhoea by type of diarrhoea in a sample of episodes

\begin{tabular}{lccccccc} 
& \multicolumn{2}{c}{ Intervention } & & \multicolumn{2}{c}{ Comparison } \\
\cline { 2 - 3 } Type of diarrhoea & No of episodes & $\begin{array}{c}\text { Mean (SD) episode } \\
\text { duration (days) }\end{array}$ & & No of episodes & $\begin{array}{c}\text { Mean (SD) episode } \\
\text { duration (days) }\end{array}$ & Hazards ratio* (95\% Cl) \\
\hline Non-dysenteric & 560 & $4.6(3.6)$ & & 582 & $5.8(4.7)$ & $0.77(0.64$ to 0.92$)$ \\
\hline Dysentery & 60 & $6.0(4.3)$ & & 50 & $7.3(4.2)$ & $0.62(0.44$ to 0.89$)$ \\
\hline All & 620 & $4.7(3.7)$ & & 632 & $5.9(4.6)$ & $0.76(0.65$ to 0.90$)$ \\
\hline
\end{tabular}

*Adjusted for child's age, sex, and birth order, mother's education, and household homestead land size.

intervention clusters, but the difference was not statistically significant (table 5).

A total of 70 children died-33 in the intervention clusters and 37 in the comparison clusters. Thirty deaths were due to drowning, and the remaining 40 were not injury related. Because deaths due to injury (all drowning) were unlikely to be associated with zinc treatment, we restricted the mortality analysis to non-injury deaths. The non-injury death rate was $51 \%$

\begin{tabular}{|c|c|c|c|c|}
\hline Disease & Intervention & Comparison & $\begin{array}{l}\text { Rate ratio } \\
(95 \% \mathrm{Cl})^{*}\end{array}$ & $\begin{array}{c}\text { Difference in mean } \\
\text { rates }(95 \% \mathrm{CI}) \dagger\end{array}$ \\
\hline \multicolumn{5}{|l|}{ Diarrhoea: } \\
\hline Periods observed & 20699 & 21089 & & \\
\hline Periods with diarrhoea & 3278 & 3947 & & \\
\hline Unadjusted incidence (\%) & 15.8 & 18.7 & $0.85(0.76$ to 0.96$)$ & $2.9(0.8$ to 5.1$)$ \\
\hline \multicolumn{5}{|c|}{ Acute lower respiratory infection: } \\
\hline Periods observed & 20699 & 21089 & & \\
\hline $\begin{array}{l}\text { Periods with acute lower } \\
\text { respiratory infection }\end{array}$ & 1543 & 1700 & & \\
\hline Unadjusted incidence (\%) & 7.5 & 8.1 & $0.93(0.78$ to 1.10$)$ & $0.7(-0.7$ to 2.0$)$ \\
\hline \multicolumn{5}{|c|}{$\begin{array}{l}\text { *Based on individual level analysis using random effect Poisson regression model. Adjusted for child's age, } \\
\text { sex, and birth order, mother's education, household homestead land size, baseline cluster level diarrhoea } \\
\text { admission rates, and intra-cluster correlation. } \\
\text { †Based on cluster level } t \text { test analysis. Differences in mean rates expressed per } 100 \text { child years of } \\
\text { observation. Adjusted for child's age, sex, and birth order, mother's education, household homestead land } \\
\text { size, and baseline cluster level diarrhoea admission rates. }\end{array}$} \\
\hline
\end{tabular}

Table $\mathbf{5}$ Effect of zinc on diarrhoea related and acute lower respiratory infection related admission to hospital

\begin{tabular}{|c|c|c|c|c|}
\hline Disease & Intervention & Comparison & Rate ratio $(95 \% \mathrm{Cl})^{*}$ & $\begin{array}{c}\text { Difference in } \\
\text { mean rates } \\
(95 \% \mathrm{Cl}) \dagger\end{array}$ \\
\hline \multicolumn{5}{|l|}{ Diarrhoea: } \\
\hline Child years observed & 5866 & 6015 & & \\
\hline Admissions & 478 & 622 & & \\
\hline Unadjusted admission rate & 8.15 & 10.34 & 0.76 (0.59 to 0.98$)$ & $2.2(-0.04$ to 4.5$)$ \\
\hline \multicolumn{5}{|l|}{ Acute lower respiratory infection: } \\
\hline Child years observed & 5866 & 6015 & & \\
\hline Admissions & 296 & 360 & & \\
\hline Unadjusted admission rate & 5.05 & 5.99 & 0.81 (0.53 to 1.23$)$ & $0.9(-1.8$ to 3.6$)$ \\
\hline
\end{tabular}

*Based on individual level analysis using random effect Poisson regression model. Adjusted for child's age, sex, and birth order, mother's education, household homestead land size, baseline cluster level diarrhoea admission rates, and intra-cluster correlation.

tBased on cluster level $t$ test analysis. Differences in mean rates expressed per 100 child years of observation. Adjusted for child's age, sex, and birth order, mother's education, household homestead land size, and baseline cluster level diarrhoea admission rates.

Table 6 Effect of zinc on non-injury child deaths

\begin{tabular}{lcccc} 
Non-injury deaths & Intervention & Comparison & Rate ratio* $\mathbf{( 9 5 \%} \mathbf{~ C l )}$ & $\begin{array}{c}\text { Difference of mean } \\
\text { rates } \mathbf{( 9 5 \%} \mathbf{~ C l}) \dagger\end{array}$ \\
\hline Child years observed & 5866 & 6015 & & \\
\hline Non-injury deaths & 13 & 27 & & \\
\hline Non-injury death rates & 2.22 & 4.49 & $0.49(0.25$ to 0.94$)$ & 2.2 (0.6 to 3.7) \\
\hline
\end{tabular}

*Based on individual level analysis using random effect Poisson regression model. Adjusted for child's age, sex, and birth order, mother's education, household homestead land size, baseline cluster level diarrhoea admission rates, and intra-cluster correlation.

†Based on cluster level $t$ test analysis. Differences of mean rates expressed per 1000 child years of observation. Adjusted for child's age, sex, and birth order, mother's education, household homestead land size, and baseline cluster level diarrhoea admission rates. lower in the zinc intervention clusters than in the comparison clusters (13 v 27) (table 6).

The lower non-injury death rate in the intervention clusters was almost entirely due to fewer deaths from diarrhoea and acute lower respiratory infection. Diarrhoea and acute lower respiratory infection together accounted for 10 deaths in the intervention clusters and 20 deaths in the comparison clusters (table 7).

We investigated whether there was a pre-existing difference in child mortality between these two areas or a difference in children in an age group not included in the study by using existing data from the Matlab health and demographic surveillance system. The non-injury death rates in children aged 3-59 months in zinc intervention and comparison households in the two years preceding the start of the trial (November 1996 to October 1998) were 3.8 and 4.0 per 1000 child yearsnot significantly different. We also assessed deaths in children in the first three months of life during the period of the trial, given that they were not treated with zinc. There were 62 deaths in children $<3$ months of age in the zinc intervention and 63 in the comparison areas, resulting in death rates of 151 and 147 per 1000 child years observed, which were not significantly different.

\section{Discussion}

In our study population, children who received zinc supplementation during and after diarrhoea had 24\% shorter duration of diarrhoea, $15 \%$ lower incidence of diarrhoea, and a trend suggesting fewer diarrhoea related hospital admissions. The reductions in duration of both non-dysenteric diarrhoea and dysentery were significant. The downward trend in the incidence of acute lower respiratory infection in the zinc treatment

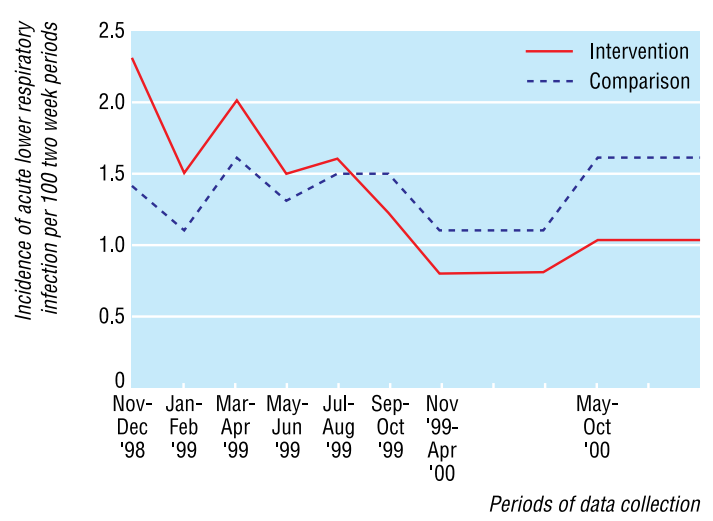

Fig 2 Incidence of acute lower respiratory infection by area and study period 
Table 7 Causes of non-injury deaths by area

\begin{tabular}{lccc} 
Causes of death & Intervention & Comparison & Total \\
\hline Diarrhoea & 3 & 9 & 12 \\
\hline $\begin{array}{l}\text { Acute lower respiratory } \\
\text { infection }\end{array}$ & 7 & 10 & 17 \\
\hline $\begin{array}{l}\text { Diarrhoea and acute } \\
\text { lower respiratory } \\
\text { infection }\end{array}$ & 0 & 1 & 1 \\
\hline Measles & 1 & 0 & 1 \\
\hline Malnutrition & 0 & 1 & 1 \\
\hline Fever of unknown origin & 0 & 1 & 1 \\
\hline Not identified & 2 & 5 & 7 \\
\hline Total & 13 & 27 & 40 \\
\hline
\end{tabular}

group, but not in the comparison group, and the $19 \%$ reduction in admissions for acute lower respiratory infection, although not statistically significant, also suggested a benefit of zinc.

The reduction in the duration of diarrhoeal episode is consistent with earlier studies. ${ }^{11}{ }^{12} \mathrm{~A}$ meta-analysis of five studies of zinc treatment for acute diarrhoea found a summary estimate for reduction in duration of $16 \% .{ }^{3}$ Possible mechanisms for the effect of zinc treatment on the duration of diarrhoea include improved absorption of water and electrolytes by the intestine, ${ }^{13}$ faster regeneration of gut epithelium, ${ }^{14}$ increased levels of enterocyte brush border enzymes, ${ }^{15}$ and enhanced immune response, ${ }^{16}$ leading to early clearance of diarrhoeal pathogens from the intestine. ${ }^{17}$

Several recent controlled trials have shown a preventive effect of routine zinc supplementation on the incidence of diarrhoea ${ }^{4819}$ and acute lower respiratory infection..$^{21}$ However, these studies provided daily zinc supplementation for a period of 6-12 months, which is often not feasible in large scale programmes. Three studies in which zinc was given for two weeks during and after diarrhoea found reductions in episodes of diarrhoea or respiratory disease in subsequent two to three month periods without additional zinc supplements. ${ }^{4}$ The lower rates of diarrhoea and acute lower respiratory infection in this and other studies indicate that a reduction in incidence could be due to a systemic effect of zinc, probably through enhanced immune function. ${ }^{11} 1216$ The reduction in hospital admissions for diarrhoea could have been due to effects of zinc on episode duration, reduced incidence, or altered care seeking behaviour. A recent study from Bangladesh reported a higher prevalence of acute lower respiratory infection in Bangladeshi children in a six month follow up period after receipt of $20 \mathrm{mg}$ elemental zinc daily for 14 days. ${ }^{22}$ The prevalence of acute lower respiratory infection was, however, lower in children who received a 200000 IU vitamin A capsule after 14 days of zinc supplementation. A national programme in Bangladesh gives a six monthly vitamin A distribution to children aged 6 months to 6 years. Almost all our study children received vitamin A capsules every six months, so the findings of that study may not be inconsistent with ours. In that study, all children received daily supplements for 14 days at the beginning of a six month follow up period. ${ }^{22}$ In contrast, we supplemented children during each episode of diarrhoea, a targeted approach to zinc supplementation that is much more feasible to implement.
What is already known on this topic

Zinc deficiency is highly prevalent in children in developing countries

Zinc supplements given during diarrhoea reduce the duration and severity of treated episodes

If given for 14 days during and after diarrhoea, zinc reduces the incidence of diarrhoea and pneumonia in the subsequent two to three months

What this study adds

Zinc used as a treatment for diarrhoea reduces mortality in children

Zinc reduces admissions to hospital for diarrhoea

The impact of zinc on mortality and morbidity can be achieved in a realistic large scale public health programme

The most important aspect of our study is that it shows for the first time a reduction in non-injury deaths from the use of zinc as a treatment for diarrhoea. About half the number of non-injury deaths occurred in the intervention clusters than in the comparison clusters. This difference was significant, even in the rigorous statistical analysis for the cluster level design, controlling for confounding variables. We believe, therefore, that the lower mortality can be attributed to zinc supplementation. The magnitude of the effect of zinc was greater for mortality than for morbidity, which may reflect a greater reduction in severity than incidence of disease. Vitamin A supplementation is a precedent for this-it had small effects on diarrhoea morbidity and none on acute lower respiratory infection morbidity, yet it resulted in about $23 \%$ reduction in mortality in children aged 6 months to 5 years. ${ }^{23}$ A recently published randomised trial from India found a large reduction in overall mortality in infants who were small for gestational age and supplemented daily with zinc from 1 to 9 months of age. $^{24}$

The intervention we evaluated is simple and inexpensive and can be incorporated into existing diarrhoeal disease control efforts. Further study is needed to determine whether zinc should be given as a supplement or can be incorporated into oral rehydration solution.

Contributors: AHB and REB had the idea for and implemented the study, conducted the analysis, and drafted the manuscript. SEA, MY, and JC supervised field activities. SA assisted with data analysis. JPV provided technical and administrative support. All authors contributed to the interpretation and presentation of the manuscript. AHB will act as guarantor for the paper.

Funding: Johns Hopkins Family Health and Child Survival Cooperative Agreement and ICDDR,B Cooperative Agreement, with funding from the US Agency for International Development.

Competing interests: None declared.

1 Sandstead HH. Zinc deficiency: a public health problem? Am J Dis Child 1991;145:853-9.

2 Castillo-Duran C, Vial P, Uauy R. Trace mineral balance during acute diarrhoea in infants. J Pediatr 1988;113:452-7.

3 Zinc Investigators' Collaborative Group. Therapeutic effects of oral zinc in acute and persistent diarrhoea in children in developing countries: 
pooled analysis of randomized controlled trials. Am J Clin Nutr 2000;72:1516-22.

4 Zinc Investigators' Collaborative Group. Prevention of diarrhoea and pneumonia by zinc supplementation in children in developing countries: pooled analysis of randomized controlled trials. J Pediatr 1999;135:68997.

5 Health and Demographic Surveillance System Matlab. Registration of demographic events and contraceptive use 1998. Bangladesh: International Center for Diarrhoeal Disease Research, 2000. (ICDDR,B Scientific Report No. 87.)

6 Donner A, Birkett N, Buck C. Randomization by cluster. Am J Epidemiol 1981;114:906-13.

7 Baqui AH, Black RE, Arifeen SE, Hill K, Mitra SN, Sabir AA. Causes of childhood deaths in Bangladesh: results of a nationwide verbal autopsy study, Bull World Health Org 1998;76:161-71.

8 Cox DR, Oakes D. Analysis of survival data. London: Chapman and Hall, 1984 .

9 Clayton D. Poisson regression with a random effect. Stata Technical Bulletin 1998;8:202-7.

10 Thompson SG, Pyke SDM, Hardy RJ. The design and analysis of paired cluster randomized trial: an application of meta-analysis techniques. Stat Med 1997:16:2063-79.

11 Sazawal S, Black RE, Bhan MK, Bhandari N, Sinha A, Jalla S. Zinc supplementation in young children with acute diarrhoea in India. $N$ Engl J Med 1995;333:839-44.

12 Roy SK, Tomkins AM, Akramuzzaman SM, Behrens RH, Mahalanabis D, Fuchs G. Randomised controlled trial of zinc supplementation in malnourished Bangladeshi children with acute diarrhoea. Arch Dis Child 1997;77:196-200.

13 Golden BE, Golden MHN. Zinc, sodium and potassium losses in the diarrhoeas of malnutrition and zinc deficiency. In: Mills CF, Bremner I, Chesters JK, eds. Trace elements in man and animals TEMA 5. Aberdeen: Rowett Research Institute, 1985:228-32.

14 Bettger WJ, O'Dell BL. A critical physiological role of zinc in the structure and function of biomembranes. Life Sci 1981;28:1425-38.

15 Gebhard RL, Karouani R, Prigge WF, McClain CJ. Effect of severe zinc deficiency on activity of intestinal disaccharidases and 3-hydroxy-3methyl-glutaryl coenzyme A reductase in the rat. J Nutr 1983;113:855-9.
16 Shanker AH, Prasad AS. Zinc and immune function: the biological basi of altered resistance to infection. Am J Clin Nutr 1998;68(suppl 2):447-63S.

17 Fenwick PK, Agget PJ, McDonald D, Huber C, Wakelin D. Zinc deficiency and zinc repletion: effect on the response of rats to infection with Strongyloids ratti. Am J Clin Nutr 1990;52:166-72.

18 Sazawal S, Black RE, Bhan MK, Jalla S, Sinha A, Bhandari N. Efficacy of zinc supplementation in reducing the incidence and prevalence of acute diarrhoea-a community-based, double-blind, controlled trial. Am J Clin Nutr 1997;66:413-18.

19 Rosado JL, Lopez P, Munoz E, Martinez H, Allen LH. Zinc supplementation reduced morbidity, but neither zinc nor iron supplementation affected growth or body composition of Mexican preschoolers. Am J Clin Nutr 1997;65:13-9.

20 Ruel MT, Rivera JA, Santizo MC, Lonnerdal B, Brown KH. Impact of zinc supplementation on morbidity from diarrhoea and respiratory infections among rural Guatemalan children. Pediatrics 1997;99:808-13.

21 Sazawal S, Black RE, Jalla S, Mazumdar S, Sinha A, Bhan MK. Zinc supplementation reduces the incidence of acute lower respiratory infection in infants and preschool children: a double-blind controlled trial. Pediatrics 1998;102:1-5.

22 Rahman MM, Vermund SH, Wahed MA, Fuchs GJ, Baqui AH, AlvarejJO Simultaneous zinc and vitamin A supplementation in Bangladeshi children: randomised double blind controlled trial. BMJ 2001·323:314-8.

23 Beaton RH, Martorell R, Aronson KJ, Edmonston B, McCabe G, Ross AC, et al. Effectiveness of vitamin A supplementation in the control of young child morbidity and mortality in developing countries. United Nations ACC/Subcommittee on Nutrition, Nutrition Policy, 1993. (Discussion paper No 13.)

24 Sazawal S, Black RE, Menon VP, Dinghra P, Caulfield LE, Dhingra U, et al. Zinc supplementation in infants born small for gestational age reduces mortality: a prospective, randomized, controlled trial. Pediatrics 2001;108:1280-6.

(Accepted 24 June 2002)

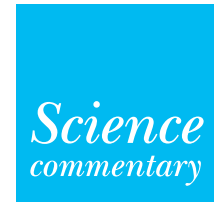

Abi Berger science editor, $B M$

\section{Science commentary: What does zinc do?}

Abi Berger

Adequate zinc intake is critical for health. Zinc deficiency affects cells of the immune system. It causes a reduction in the number $\mathrm{B}$ lymphocytes and $\mathrm{T}$ lymphocytes (CD4 lymphocytes in particular) through increased apoptosis and also reduces their functional capacity. The functions of the macrophage, another key immunological cell that engulfs and destroys bacteria, are also compromised. The production and potency of several cytokines, the central messengers of the immune system, are also perturbed by zinc deficiency. Many of these changes occur even in the early stages of deficiency.

Zinc plays a part in the maintenance of epithelial and tissue integrity through promoting cell growth and suppressing apoptosis and through its underappreciated role as an antioxidant, protecting against free radical damage during inflammatory responses. Thus, in the case of diarrhoea, multiple functions of zinc may help to maintain the integrity of the gut mucosa to reduce or prevent fluid loss. Notably, these responses can occur within 48 hours, much more rapidly than the direct effects of zinc on cellular development.

The recommended daily allowance is only $10 \mathrm{mg}$ elemental zinc, but many people in both developing and industrialised countries do not have this in their diet. ${ }^{1}$ Zinc deficiency is biochemically defined as a serum concentration of less than $9 \mu \mathrm{mol} / \mathrm{l}$. However, serum zinc concentrations may not fully reflect the physiological zinc status in an individual, and individuals with apparently normal serum concentrations may benefit from daily zinc supplements. ${ }^{2}$

\section{Benefits of supplementation}

This is clearly illustrated in several randomised controlled trials of zinc supplementation. A metaanalysis indicated that daily zinc supplementation can reduce the incidence of pneumonia by $41 \%$ and diarrhoea by $18 \%{ }^{3}$ A meta-analysis of trials of adjunctive zinc supplementation in children with diarrhoea reduced the duration of the illness by $24 \%{ }^{4} \mathrm{~A}$ trial of daily zinc supplementation in otherwise healthy children from New Guinea reduced the number of cases of malaria seen at a health clinic by $38 \%{ }^{5}$

There is also evidence that zinc supplementation could offer benefit to pregnant women and their babies. $^{6}$ One study showed that prenatal zinc supplementation can increase birth weight, ${ }^{7}$ and another indicated reduced incidence of diarrhoea and other morbidities in the infants. ${ }^{8}$ Babies who are small for gestational age also seem to benefit from taking daily zinc supplementation. A trial in India found that babies who received zinc from 1 month onwards were $60 \%$ less likely to die during infancy. ${ }^{9}$ Lastly, several studies indicate a potential role for zinc and supplements that contain zinc in improving immune status ${ }^{10}$ and health in elderly people. ${ }^{11}$ Zinc supplementation, therefore, seems be particularly critical during periods of immune development or degeneration: early childhood, pregnancy, and later life.

\section{Problems caused by too much zinc}

Taking too much daily zinc could also be a problem because, although it is not toxic, high doses can impair 
copper absorption. This can lead to copper deficiency with immunosuppression and other subtle and apparent adverse effects, especially for the mother and fetus during pregnancy. ${ }^{12}$ For this reason, doses more than twice the recommended daily allowance are not recommended and prenatal zinc supplements should contain copper, ${ }^{13}$ especially in populations with low mineral intakes.

1 Gibson RS, Vanderkooy PD, MacDonald AC, Goldman A, Ryan BA, Berry M. A growth-limiting, mild zinc-deficiency syndrome in some southern Ontario boys with low height percentiles. Am J Clin Nutr 1989;49:1266-75.

2 Black RE, Sazawal S. Zinc and childhood infectious disease morbidity and mortality. Br J Nutr 2001;85(suppl 2):S125-9.

3 Bhutta ZA, Black RE, Brown KH, Gardner JM, Gore S, Hidayat A, et al. Prevention of diarrhea and pneumonia by zinc supplementation in children in developing countries: pooled analysis of randomized controlled trials. Zinc Investigators' Collaborative Group. J Pediatr 1999;135:689-97.

4 Bhutta ZA, Bird SM, Black RE, Brown KH, Gardner JM, Hidayat A, et al Therapeutic effects of oral zinc in acute and persistent diarrhea in children in developing countries: pooled analysis of randomized controlled trials. Am J Clin Nutr 2000;72:1516-22.

5 Shankar AH, Genton B, Baisor M, Paino J, Tamja S, Adiguma T, et al. The influence of zinc supplementation on morbidity due to Plasmodium falciparum: a randomized trial in preschool children in Papua New Guinea. Am J Trop Med Hyg 2000;62:663-9.
6 Caulfield LE, Zavaleta N, Shankar AH, Merialdi M. Potential contribution of maternal zinc supplementation during pregnancy to maternal and child survival. Am J Clin Nutr 1998;68(2 suppl):S499-508.

7 Goldenberg RL, Tamura T, Neggers Y, Copper RL, Johnston KE, DuBard $\mathrm{MB}$, et al. The effect of zinc supplementation on pregnancy outcome. JAMA 1995;274:463-8.

8 Osendarp SJ, van RaaijJM, Darmstadt GL, Baqui AH, Hautvast JG, Fuchs GJ. Zinc supplementation during pregnancy and effects on growth and morbidity in low birthweight infants: a randomised placebo controlled trial. Lancet 2001;357:1080-5

9 Sazawal S, Black RE, Menon VP, Dinghra P, Caulfield LE, Dhingra U, et al. Zinc supplementation in infants born small for gestational age reduces mortality: a prospective, randomized, controlled trial. Pediatrics 2001;108:1280-6.

10 Fortes C, Forastiere F, Agabiti N, Fano V, Pacifici R, Virgili F, et al. The effect of zinc and vitamin A supplementation on immune response in an older population. J Am Geriatr Soc 1998;46:19-26.

11 Girodon F, Galan P, Monget AL, Boutron-Ruault MC, Brunet-Lecomte P, Preziosi P, et al. Impact of trace elements and vitamin supplementation on immunity and infections in institutionalized elderly patients: a randomized controlled trial. MIN. VIT. AOX. geriatric network. Arch Intern Med 1999;159:748-54

12 Keen CL, Uriu-Hare JY, Hawk SN, Jankowski MA, Daston GP, Kwik-Uribe CL, et al. Effect of copper deficiency on prenatal development and pregnancy outcome. Am J Clin Nutr 1998;7(suppl 5):S1003-11.

13 Institute of Medicine, Subcommittee on Nutritional Status and Weight Gain During Pregnancy. Nutrition during pregnancy. Part 1:weight gain. Par 11:nutrition supplements. Washington, DC: National Academy Press, 1990. 